\title{
Characterization and Analysis of the COD Chemical Composition in the Polymer-Containing Oil Production Wastewater
}

\author{
Xianqing Yin', Bo Jing', ${ }^{2,}$, Dawei Wang ${ }^{2,3}$, Xueqi Huang1, Mijia Zhu ${ }^{1 *}$ \\ 'State Key Laboratory of Petroleum Pollution Control (Yangtze University), School of Chemistry \\ and Environmental Engineering, Yangtze University, Jingzhou, Hubei 434023, China \\ ${ }^{2}$ State Key Laboratory of Offshore Oil Exploitation, Beijing 100027, China \\ ${ }^{3} \mathrm{CNOOC}$ Research Institute, Beijing 100027, China
}

Received: 13 February 2021

Accepted: 15 April 2021

\begin{abstract}
The analysis of the composition of chemical oxygen demand (COD) can provide a theoretical basis for the design of an efficient wastewater treatment process. In this study, the gradient membrane molecular weight division method was selected to create the COD fingerprint of the oil production wastewater. The chemical components and concentrations of the organic pollutants in the wastewater were analysed by gas chromatography-mass spectrometry, and the structures were qualitatively analysed by UV-Vis. Results showed that the types of aromatic hydrocarbons decreased from 163 to 96 in the advanced wastewater treatment, the types of straight-chain hydrocarbon organics were increased from 17 to 25, which changed from $\mathrm{C} 14-\mathrm{C} 30$ to $\mathrm{C} 14-\mathrm{C} 38$. By contrast, the total concentration of COD was decreased by $80.5 \%$ (from $237.5 \mathrm{mg} / \mathrm{L}$ to $46.3 \mathrm{mg} / \mathrm{L}$ ). The organic pollutants in the wastewater were mainly aromatic hydrocarbons and straight-chain alkanes. The results also indicated that the removal of the petroleum macromolecules and soluble organics will be necessary for the treatment of the polymercontaining oil production wastewater.
\end{abstract}

Keywords: polymer-containing oil production wastewater, gradient membrane molecular weight division method, chemical oxygen demand, aromatic hydrocarbons

\section{Introduction}

Polymer-flooding wastewater whose direct discharge seriously affects the environment has a complex composition and poor biodegradability [1]. Chemical oxygen demand (COD) is a widely used important

*e-mail: zhumijia128@163.com indicator reflecting the concentration of organics in wastewater. However, hazardous substances, such as tiny amounts of aromatic hydrocarbons dissolved in water, are independent of COD. These substances can pollute the aquatic organisms and threaten human health when discharging into the sea and surrounding environment [2]. Therefore, a qualitative and quantitative analysis of the specific pollutants in wastewater, especially those affecting the COD of wastewater, should be conducted. 
An analysis of the COD composition of the wastewater can evaluate the effectiveness of wastewater treatment and provide the scientific basis for determining a rational wastewater treatment process.

In the wastewater treatment process, the identification of the chemical composition of complex organic pollutants and their contribution to COD is a significant step. Amongst the physical and chemical methods, gradient membrane separation technology and gel permeation chromatography are used for analyzing different components according to their molecular weights $[3,4]$. The gradient membrane separation technology intercepts organic matter through sections of membranes with different molecular weights and pore sizes, thereby revealing the mechanism of pollutant migration and transformation $[5,6]$. This mechanism is a simple and effective characterization method used to study the properties of components in different particle sizes and evaluate the effectiveness of wastewater treatment. The most common membrane material for deep filtration is Polyethersulfone (PES) which has stable physical and chemical properties and good compatibility. It is a widely used membrane material in the sewage treatment industry. PES can be obtained by condensing 4,4'-bissulfonyl chloride diphenyl ether with diphenyl ether under the catalysis of anhydrous ferric chloride. It is resistant to high temperature, can be used continuously at $180 \sim 200^{\circ} \mathrm{C}$, can withstand hot water or steam at $150 \sim 160^{\circ} \mathrm{C}$, and is not corroded by acids and alkalis at high temperatures. It is non-toxic, nonflammable, resistant to gasoline, engine oil, lubricating oil and other oils and Freon and other cleaning agents, and its resistance to solvent cracking is the best among amorphous resins. Therefore, the ultrafiltration membrane made of polyethersulfone can withstand high temperature, acid, alkali, oil and other organic solvents, and can treat wastewater with various bad conditions.

Pan et al. [7] used polyethersulfone hollow fiber ultrafiltration membrane modules to treat oilfield produced water, and discussed the pretreatment effects of ultrafiltration membranes for oilfield reinjection water treatment and produced water reuse. The results show that the polyethersulfone ultrafiltration membrane has a higher water flux, and the petroleum, suspended solids and the median particle size of the treated water reach the standard of reinjection water, but due to the higher $\mathrm{H}_{2} \mathrm{~S}$ and chemical oxygen demand in the produced water (COD) content, the pollution index of ultrafiltration product water is greater than 3.0, which exceeds the water inlet requirements of the subsequent nanofiltration/reverse osmosis membrane system. Xu et al. [8] used polyethersulfone ultrafiltration membranes to concentrate poplar alkaline hydrogen peroxide mechanical pulp and chemical thermomechanical pulp (P-RC-APMP) pulping waste, and optimized the process. In addition, it has also been widely used in many fields such as medicine, chemical industry, biology and food.
UV-Vis conducts preliminary qualitative research on the structure of organic pollutants through the characteristic peaks of components in wastewater. The organic pollutants in wastewater are qualitatively and quantitatively analyzed by gas chromatographymass spectrometry (GC-MS) [9, 10]. The dissociation rate of tiny amounts of organics in different types of wastewater is related to its molecular weight. The dissociation rate of the trace organic matter in different types of wastewater is related to its molecular weight. Pollutants with small molecular weights have large specific surface areas. When the molecular weight of the pollutant is small, its specific surface area is large [3, 11]. Pollutants with smaller molecular weights are easier to dissociate than those with larger ones. Continuous research on the molecular weight of pollutants may promote the formulation of suitable wastewater treatment technology, provide insight into the material migration changes in the wastewater and evaluate the effectiveness of wastewater treatment [12, 13].

The water quality parameters of the separated particles of different molecular weights are detected and analyzed for different parameters, including COD, BOD, UV254, TOC and TN. The suitable wastewater treatment technology can be selected according to the different parameters of the molecular weight distribution [14, 15]. However, a single parameter in all of them cannot be used to determine the specific material composition of wastewater. If a large amount of soluble small molecules is present in wastewater, other analytical tools are needed, such as GC-MS, gel permeation chromatography, particle technology instruments and infrared spectroscopy. These methods are used to characterize organic pollutants by their functional groups and molecular structures [16]. In the previous research, the application of the gradient membrane separation technology combined with UVVis and GC-MS to analyze the composition of organic pollutants in oily wastewater is limited.

This study aims to establish an efficient and rational wastewater treatment system by studying the composition and characteristics of COD of wastewater. In this study, we selected the polymer-containing oil production wastewater as the object of the analysis. The COD fingerprints of wastewater based on gradient membrane separation were studied. The COD value of each component after passing through the membrane was measured by gradient membrane molecular weight division method. This task was conducted to determine the distribution of different molecular weight components in the wastewater and establish a relationship between the relative molecular weight and the COD, thereby revealing the influence of various molecular weights on COD. The functional groups and molecular structures of organic pollutants were characterized by advanced instrumental analytical methods, such as UV-Vis and GC-MS, to understand the specific material composition of wastewater. 
Table 1 . Water quality characteristic parameters of polymercontaining oily wastewater.

\begin{tabular}{|c|c|c|}
\hline \multirow{2}{*}{ Parameter } & \multicolumn{2}{|c|}{ Concentration/ mg/L } \\
\cline { 2 - 3 } & Sample I & Sample II \\
\hline Oil & 15.3 & 0.2 \\
\hline COD $_{\text {cr }}$ & 237.5 & 46.3 \\
\hline SS & 15 & 11 \\
\hline Ammonia nitrogen & 68.4 & 2.4 \\
\hline Polymer & 94.3 & 12.1 \\
\hline Salt & 9425.21 & 9426.34 \\
\hline pH & 7.10 & 7.12 \\
\hline Chroma & 11 & 11 \\
\hline
\end{tabular}

\section{Experimental}

\section{Sample Collection}

Oil-removed and filtered wastewater (sample I) and external wastewater treated by electrochemical advanced oxidation treatment (sample II) of terminal treatment plant SZ36-1 of the offshore oilfield were selected, and the COD will be analyzed. Some basic characteristic parameters of the two water samples were listed in Table 1.

\section{Gradient Membrane Separation}

The water samples were classified and filtered by microfiltration and ultrafiltration separation technology. The process of wastewater grading schemes is shown in Fig. 1. The leachates of different size ranges were tested and analyzed to establish a relationship between the distribution of various molecular weights and the COD.

Molecular weight segmentation was performed by gradient membrane separation experiments by using high purity $\mathrm{N}_{2}$ as a driving force [10]. The water sample driven by $\mathrm{N}_{2}$ pressure of $0.1-0.25 \mathrm{MPa}$ was passed through a $0.45 \mu \mathrm{m}$ ultrafiltration membrane in the filter cup to remove settleable particles with a molecular weight over $0.45 \mu \mathrm{m}$, such as SS, and oil droplets to obtain the dissolved wastewater that entered the subsequent filter experiment of different molecular weights. The filtrate was filtered through an intercept with molecular weights of $0.45 \mu \mathrm{m}, 50 \mathrm{kDa}, 10 \mathrm{kDa}$, $5 \mathrm{kDa}$ and $1 \mathrm{kDa}$ ultrafiltration membranes, and all levels of the filtrates of different molecular weights were obtained. The CODs of the leachates of different size ranges were tested and analyzed to determine the distribution of various molecular weight components.

Sequential filtration for molecular weight analysis knowledge about the distribution of molecular sizes is very important for understanding the basic chemistry of organic compounds of different molecular weights in oil production wastewater (PW) and their degradation during treatment progress. The molecular size distribution of the PW was determined by sequential ultrafiltration for improved physical segregation. Specifically, the experiment was carried out on PW using gradient membrane separation via an ultrafiltration apparatus; all ultrafiltration experiments were conducted under positive pressure (0.6-1.8 atm with $\mathrm{N}_{2}$ as the inert gas) in a continuously stirred cell with a volumetric capacity of $400 \mathrm{~mL}$ using an SCMtype ultrafilter (Shanghai Institute of Applied Physics, Chinese Academy of Sciences, Shanghai, China). Briefly, PW samples were initially filtered using a $0.45 \mu \mathrm{m}$ cellulose ester membrane, and then gradientseparated by polyether sulfone membranes with nominal molecular weight cut-offs (MWCOs) of 50, 10, 5 and $1 \mathrm{kDa}$. Each PW fraction was analyzed for its COD value.

\section{COD Detection}

A DRB200 COD digester and DR3900 spectrophotometer with its supporting standard prefabricated reagent tubes $(3-50 \mathrm{mg} / \mathrm{L})$ were used. The analytical method is based on the HACH Company test program $[17,18]$.

\section{Liquid-Liquid Extraction}

Approximately $500 \mathrm{~mL}$ of the water samples was poured into a $1000 \mathrm{~mL}$ funnel. Thereafter, $100 \mathrm{~mL}$ of chromatographic grade dichloromethane was added to each sample. After shaking for $5 \mathrm{~min}$, the mixtures were subjected to static stratification, and the organic phase from each sample was collected. The extraction

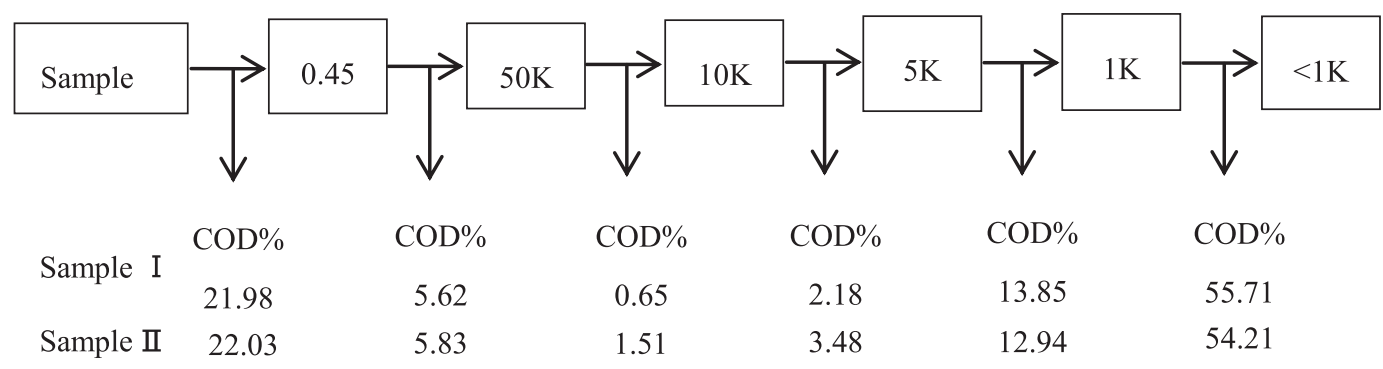

Fig. 1. Wastewater gradient membrane molecular weight division scheme. 
was repeated four times, and the organic phases of each sample were combined. Anhydrous sodium sulphate was added to the organic phases, allowed to stand for $30 \mathrm{~min}$, dehydrated and dried before use. The dichloromethane layer was concentrated on an evaporator to obtain the residues, which are the dissolved organics in the water sample.

\section{GC-MS Analysis}

A certain amount of organics condensed to dryness was poured into a chromatographic bottle (a sample of $5 \mathrm{mg} / \mathrm{mL}$ prepared with chromatographic grade dichloromethane). The internal standard substances D10-anthracene $(0.124 \mathrm{mg} / \mathrm{mL})$ and $5 \alpha$-androstane $(0.110 \mathrm{mg} / \mathrm{L})$ were added to the samples to detect representative aromatic hydrocarbons and straight-chain organics. The chemical composition and concentration of the organics in the wastewater were analyzed by GC-MS [19, 20]. The instrumental conditions were as follows:

\section{Chromatographic Conditions}

Agilent HP-5MS column \#1 (30 m × $250 \mathrm{~m} \times 0.25 \mathrm{~m})$; Agilent 19091S-436 UIHP-5MS column \#2 $(60 \mathrm{~m} \times 250 \mathrm{~m}$ $\times 0.25 \mathrm{~m}$ ); program temperature: $50^{\circ} \mathrm{C}$ for $1 \mathrm{~min}, 20^{\circ} \mathrm{C} /$ min to $100^{\circ} \mathrm{C}$ and $3^{\circ} \mathrm{C} / \mathrm{min}$ to $315^{\circ} \mathrm{C}$, maintained for $28.5 \mathrm{~min}$. Carrier gas: high purity helium, total flow rate of $34 \mathrm{~mL} / \mathrm{min}$, split ratio of 15:1 and split flow rate of $14.89 \mathrm{~mL} / \mathrm{min}$.

\section{Mass Spectrometric Conditions}

Ion source temperature of $230^{\circ} \mathrm{C}$; quadrupole temperature of $150{ }^{\circ} \mathrm{C}$; EMV mode: gain factor of 1.00 ; EM voltage of 1765; solvent delay time of $10 \mathrm{~min}$; mass scanning range of $50-550 \mathrm{~m} / \mathrm{z}$. A matching degree (SI) of more than $85 \%$ organics is used as a qualitative basis by the GC-MS computer library search.

\section{$\mathrm{UV}-\mathrm{Vis}$ Analysis}

The wastewater before and after treatment was totally scanned in the 190-400 $\mathrm{nm}$ wavelength range in a cuvette, and the spectral width was $2 \mathrm{~nm}$. The characteristics of the chromophore and auxochrome in the pollutant molecule were analyzed through the change of the absorption curve.

\section{Steady and Time-Correlated Fluorescence Study of Produced Water}

Steady-state fluorescence spectra were recorded on a Hatch F4500 fluorimeter (Hitachi, Tokyo, Japan) at $20 \pm 0.2^{\circ} \mathrm{C}$. Samples for fluorescence measurements were placed in $1 \mathrm{~cm} \times 1 \mathrm{~cm}$ quartz cells. All samples were excited at $250 \mathrm{~nm}$ and the fluorescence spectra were recorded at between $290 \mathrm{~nm}$ and $500 \mathrm{~nm}$ for PW samples both before and after treatment. The bandpass for the excitation and emission monochromator was ca. $2 \mathrm{~nm}$.

Time-resolved fluorescence measurements were performed with a FluoTime 200 (PicoQuant GmbH, Berlin, Germany) time-correlated single-photon counter (SPC) at a constant temperature $\left(20 \pm 0.2^{\circ} \mathrm{C}\right)$. The experiments were performed using a picosecond light emitting diode (PLS-280; PicoQuant) as the excitation source. The excitation and emission wavelengths were $280 \mathrm{~nm}$ and $375 \mathrm{~nm}$, respectively. The maximum intensity for all samples was 5,000 counts. The instrument response function (IRF) was recorded using Ludox solution by scattering the light at $280 \mathrm{~nm}$.

The fluorescence decays were fitted to Eq. (1) using PicoQuant software (Fluofit; PicoQuant) so that the lifetimes $\left(t_{\mathrm{i}}\right)$ and pre-exponential factors $\left(A_{\mathrm{i}}\right)$ could be determined. The $x^{2}$ statistic and visual inspection of the residuals were used to determine how well the calculated decay fitted the experimental data. Fits were considered acceptable when the $x^{2}$ value was between 0.9 and 1.1. A monoexponential function was first applied to fit the experimental data. If the residuals were not random, two or more exponentials were used until an acceptable fit was obtained.

$$
I(t)=I_{0} \sum_{1}^{i} A_{\mathrm{i}} \mathrm{e}^{-t / \tau_{\mathrm{i}}}
$$

\section{Results and Discussion}

\section{UV-Vis Analysis of Water Sample}

Fig. 2 shows that the characteristics of the chromophore and auxochrome in the molecular structure were analyzed through the UV-Vis analysis [21]. The basis of the qualitative structure of the molecule was reflected by the change in the shape and position of the absorption peak. The absorption peak at $204 \mathrm{~nm}$ indicated the presence of the carboxyl groups. The absorption peaks between $209 \mathrm{~nm}$ and $232 \mathrm{~nm}$ had a significant drop, thereby indicating the presence of the straight-chain alkanes containing heteroatoms and unsaturated linear organics. The decrease of the absorption peak of the wastewater after electrochemical treatment indicated that the organics were effectively degraded, and their concentrations were reduced. The peak at $288 \mathrm{~nm}$ showed that aromatic hydrocarbons containing heteroatoms and conjugated double bond substances not being completely degraded were present in the wastewater, showing a 'hyperchromic effect' by which a 'red shift' phenomenon was caused. Ona-Ruales [22] found the main reason why the solvent in the ground state caused the Stokes shift of the spectrum. This phenomenon occurred because the solvent cage of light emission-excited aromatic hydrocarbons in the ground state was reconfigured, 


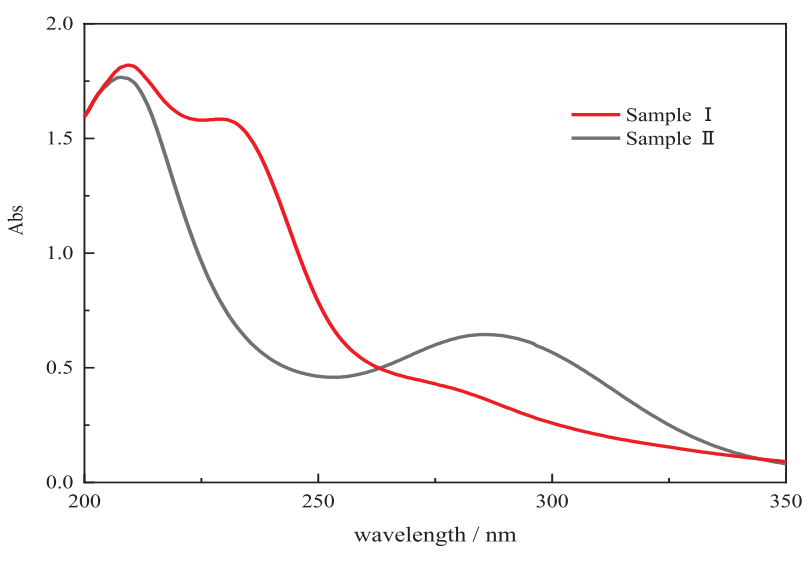

Fig. 2. UV-Vis absorption spectra of sample.

thereby resulting in the spectral shift in the spectrum. Goncalves [23] used zoom to expand the spectrum. The phenomenon that the peaks of maximum intensity were shifted was observed, which was typical in the case of temperature changes and did not affect the resolution of the curve in MCR-ALS.

\section{Distributions of COD Based on Gradient Membrane Separation}

Gradient membrane separation is an effective method for investigating the distribution of the molecular weight of pollutants. Continuous research on the distribution of molecular weight of pollutants may greatly aid in efforts towards the improvement of the wastewater treatment technology. In this study, COD was selected as a representative index because it is a reliable metric for evaluating the degree of pollution of water samples. After the microfiltration and ultrafiltration separation, the COD value of each molecular weight range was obtained by detecting and analyzing samples I and II of wastewater. This task was accomplished by comparing the COD value of each molecular weight range to the total COD value of the oily wastewater or external wastewater treated by electrochemical advanced oxidation to obtain the percentage of COD values that fell within each molecular weight range.

The oily wastewater in this experiment was from the end of the wastewater treatment system of the terminal plant. Table 1 illustrates that the oil concentration in the wastewater was relatively low (only $15.3 \mathrm{mg} / \mathrm{L}$ ). The crude oil in this area belongs to the heavy oil product, which is likely to cause serious emulsification due to high-speed movement during oil extraction and oil-water separation. The wastewater contains residual polymers and residues, such as demulsifiers and water cleaners added in the oil-water separation treatment, which have little concentration in wastewater but are easily adsorbed inorganic and organic particles. The petroleum hydrocarbons are nonpolar substances that are almost insoluble in water and can be adsorbed on some nonpolar organics in wastewater.
The experimental results indicated that the high COD value in wastewater was the result of the superposition of different molecular weight pollutants. Fig. 3a) shows that the total measured COD of water sample I was $237.5 \mathrm{mg} / \mathrm{L}$. The COD value of the molecular weight of over $0.45 \mu \mathrm{m}$ accounted for $21.98 \%$ of the total COD. The lowest COD value originated from settleable particles of the molecular weight that ranged between $5 \mathrm{kDa}$ and $0.45 \mu \mathrm{m}$ and contained residual polymers and organic chemicals, thereby accounting for $8.42 \%$ of the total COD. The COD of the molecular weight that ranged between $1 \mathrm{kDa}$ and $5 \mathrm{kDa}$ was $32.9 \mathrm{mg} / \mathrm{L}$, thereby accounting for $13.89 \%$ of the total COD. The COD of substances with a molecular weight of less than $1 \mathrm{kDa}$, defined as soluble micromolecules (or molecular fragments), was the highest, which accounted for $55.71 \%$ of total COD. Therefore, the pollutants with a molecular weight of over $0.45 \mu \mathrm{m}$ and less than $1 \mathrm{kDa}$ in wastewater greatly contribute to the COD. Fig. 3b) shows that the COD value of the molecular weight over $0.45 \mu \mathrm{m}$ accounted for $22.03 \%$ of the total COD. The COD of the components with a molecular weight less than $1 \mathrm{kDa}$ accounted for $54.21 \%$ of the total COD. These two types of pollutants greatly contributed to the total COD. The pollutants mainly come from
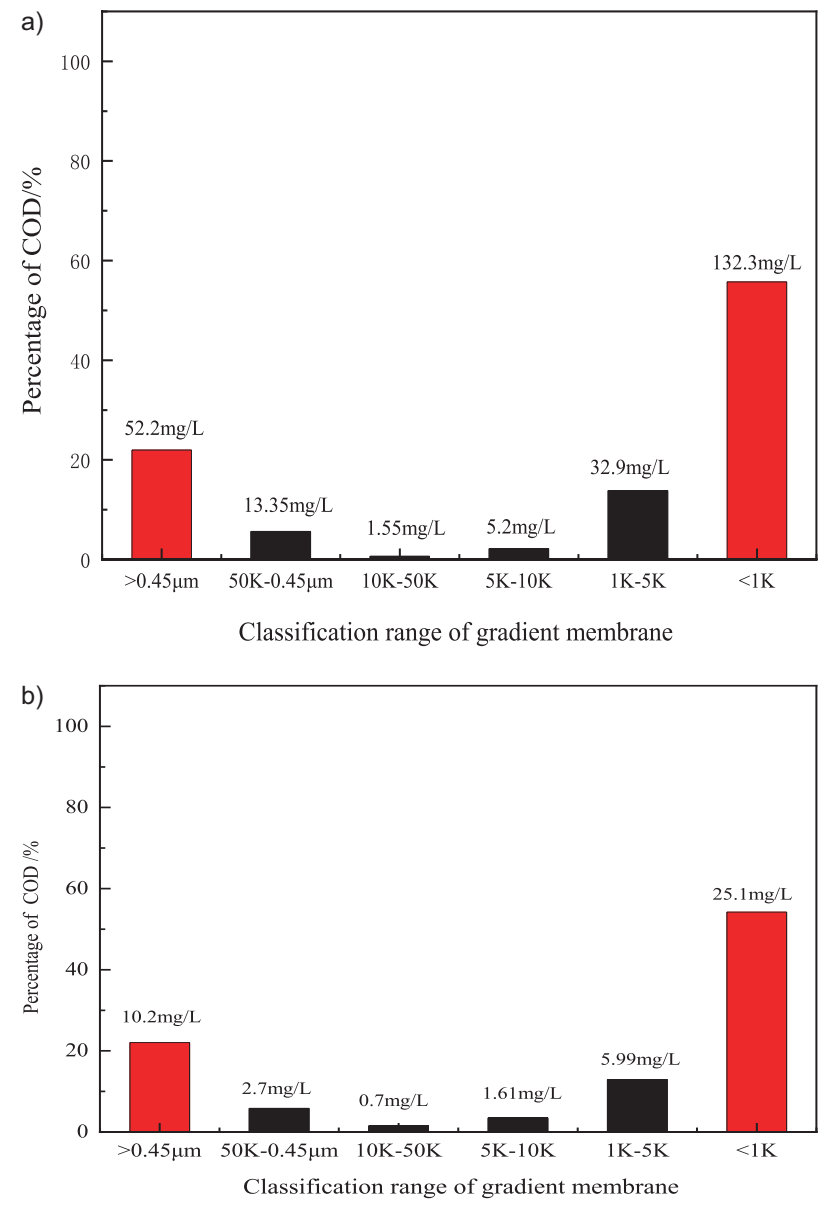

Fig. 3. COD distribution of water samples after gradient membrane separation (a- Sample I; b- Sample II). 


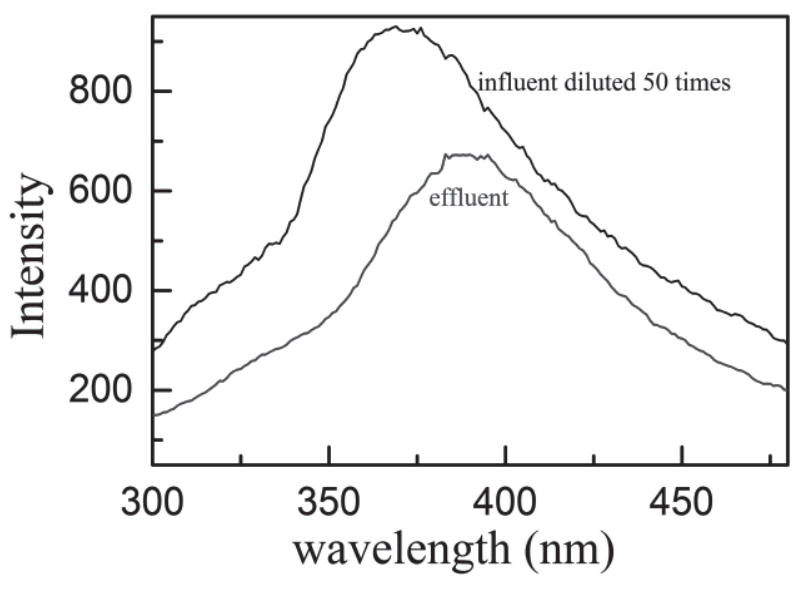

Fig. 4. Stationary fluorescence spectra of PW water influent dilute 50 times and effluent.

micromolecules whose molecular weight is less than $1 \mathrm{kDa}$ and are not completely degraded $[24,25]$. The COD in the water samples was mainly contributed by components with a molecular weight less than 1 $\mathrm{kDa}$ according to the molecular weight distribution characteristics of COD in samples I and II. This situation indicated that the micromolecular organics degraded from macromolecular organics in wastewater are difficult to completely degrade. The macromolecular organics in wastewater COD was effectively degraded by advanced electrochemical treatment, and the COD removal rate was as high as $80.5 \%$. Hence, the soluble components are the keypoints in wastewater treatment to decrease COD.

\section{Fluorescence Spectra of the Soluble Phase of PW Water}

As shown in Fig. 4, there was a broad emission from $300 \sim 480 \mathrm{~nm}$ with a maximum around $370 \mathrm{~nm}$ in the influent water samples, the broad emission was still existed in the effluent samples, however, the emission intensity decreased remarkably and the maximum redshifted to $390 \mathrm{~nm}$. PW contains a lots of polycyclic aromatic hydrocarbons (PAHs), and PAHs including anthracene, pyrene, benz[a]anthracene and dibenz[a,h] anthracene all possess high emission from $350 \mathrm{~nm}$ to $500 \mathrm{~nm}$. Therefore, the broad emission band in PW water may result from the PAHs. However, the relative lower emission from $300 \mathrm{~nm}$ to $350 \mathrm{~nm}$ may result from the contribution of single ring aromatic compounds.

The fluorescence lifetimes of influent and effluent samples were also measured. Fluorescence decays in water are not monoexponential (Fig. 5), because of the complicated compositions. There were three average fluorescence lifetimes in the PW sample, of $1.2 \mathrm{~ns}, 5.6 \mathrm{~ns}$ and $17.1 \mathrm{~ns}$. The respective contributions were $21.0 \%, 44.1 \%$ and $34.9 \%$. There were three average fluorescence lifetimes in the influent sample, which were $1.2 \mathrm{~ns}, 5.6 \mathrm{~ns}$ and $17.1 \mathrm{~ns}$. The respective

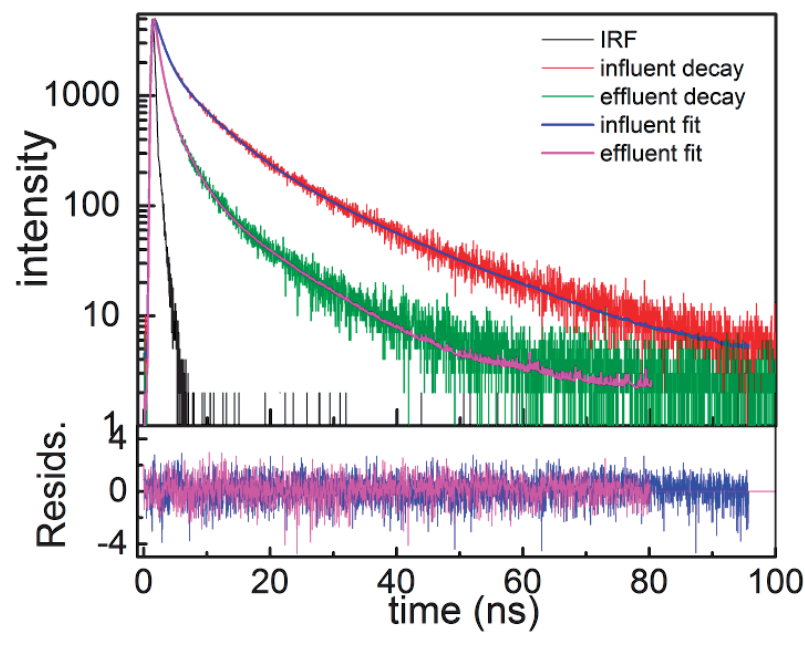

Fig. 5. Decay of fluorescence in PW influent (red) and effluent (olive green).

contributions were $21.0 \%, 44.1 \%$ and $34.9 \%$. After treatment, the fluorescence lifetimes became to $0.7 \mathrm{~ns}$, $2.6 \mathrm{~ns}$ and $10.8 \mathrm{~ns}$ with a contribution of $37.5 \%, 40.1 \%$ and $22.4 \%$. The results indicated that after treatment, PAHs or other components with longer fluorescence lifetimes decomposed to some extent since the average fluorescence lifetimes decreased and the contribution of relative shorter lifetimes increased. The blue and pink curves corresponds to the fit of the data to Eq. 1. The instrument response function is shown in black. The residuals between the experimental data and the fits are shown in the lower panel.

\section{GC-MS Composition Analysis of Water Samples I and II}

The components and concentrations of the extracted organics in the water samples were analyzed by GC-MS. The GC-MS graphs are shown in Figs S1 to S4. The component that contributed the most COD was selected to understand the main contributions of the water samples on the COD. The main substances are shown in Tables 2 and 3. The results of Figs S1 to S4 were matched by GC-MS computer library search. The analytical results were shown in Tables 3 to 5. One hundred sixty-three types of aromatic hydrocarbons and 17 types of straight-chain alkanes were detected in sample I. The prevalent pollutants that contributed the most COD in sample I include the following: naphthalene, phenanthrene, triaromatic steroids and flexor organics, whose relative concentrations were all greater than $10 \mu \mathrm{g} / \mathrm{L}$. Ninety-six types of aromatic hydrocarbons were detected in sample II, which is 67 types less than water sample I, whose total concentration was decreased by $97.1 \%$. Moreover, 25 types of straight-chain alkanes were detected in sample II, whose total concentration was increased by $92.8 \%$. However, the total COD in sample II was decreased to $46.3 \mathrm{mg} / \mathrm{L}$, with a decrease of $80.5 \%$, thereby indicating 
Table 2. Concentration comparison of organic pollutants in sample.

\begin{tabular}{|c|c|c|c|c|}
\hline \multirow{2}{*}{ Pollutants Species } & \multicolumn{2}{|c|}{ Sample I } & \multicolumn{2}{|c|}{ Sample II } \\
\cline { 2 - 5 } & Species & Concentration/ $\mu \mathrm{g} / \mathrm{L}$ & Species & Concentrationt/ $\mu \mathrm{g} / \mathrm{L}$ \\
\hline Aromatic hydrocarbons & 163 & 124.83 & 96 & 3.61 \\
\hline Alkanes (residue) & 17 & 4.52 & 39 & 64.31 \\
\hline
\end{tabular}

Table 3. Concentration comparison of aromatic hydrocarbons organics in sample.

\begin{tabular}{|c|c|c|c|c|}
\hline \multirow{2}{*}{ Organics } & \multicolumn{2}{|c|}{ Sample I } & \multicolumn{2}{c|}{ Sample II } \\
\cline { 2 - 5 } & Quantity & Concentration $/ \mu \mathrm{g} / \mathrm{L}$ & Quantity & Concentration $/ \mu \mathrm{g} / \mathrm{L}$ \\
\hline Naphthalene & 37 & 18.59 & 24 & 0.59 \\
\hline Phenanthrene & 30 & 36.57 & 18 & 1.37 \\
\hline Thiophene & 19 & 5.36 & 10 & 0.094 \\
\hline Biphenyl & 10 & 2.27 & 8 & 0.34 \\
\hline Furan & 8 & 1.93 & 6 & 0.209 \\
\hline Flexor & 17 & 10.77 & 11 & 0.17 \\
\hline Pyrene class & 7 & 5.06 & 7 & 0.418 \\
\hline Fluorene & 14 & 6.16 & 0 & 3.61 \\
\hline Triaryl steroidal & 4 & 14.26 & 0 & \\
\hline Other $\left(C_{27-29}\right)$ & 163 & 124.13 & 96 & \\
\hline$\sum$ & & & & 3 \\
\hline
\end{tabular}

that the COD of wastewater is mainly affected by macromolecular aromatic pollutants, and the point of view was also proved by Li et al. [24] and Kaur et al. [26].
The data were obtained by UV and GC-MS. The conclusion on the degradation of most aromatic organic pollutants in sample I after electrochemical treatment is as follows: Table 3 shows that the total concentration

Table 4. Concentration comparison of straight-chain organics in sample.

\begin{tabular}{|c|c|c|}
\hline \multirow{2}{*}{$\begin{array}{c}\text { Straight-chain } \\
\text { organics }\end{array}$} & \multicolumn{2}{|c|}{ Concentration $/ \mu \mathrm{g} / \mathrm{L}$} \\
\cline { 2 - 3 } & Sample I & Sample II \\
\hline $\mathrm{nC} 14$ & 0.11 & 0.52 \\
\hline $\mathrm{nC} 15$ & 0.161 & 2.63 \\
\hline $\mathrm{nC} 16$ & 0.16 & 3.76 \\
\hline $\mathrm{nC} 17$ & 0.31 & 4.07 \\
\hline $\mathrm{nC} 18$ & 0.23 & 2.28 \\
\hline $\mathrm{nC} 19$ & 0.32 & 2.04 \\
\hline $\mathrm{nC} 20$ & 0.25 & 1.81 \\
\hline $\mathrm{nC} 21$ & 0.31 & 2.71 \\
\hline $\mathrm{nC} 22$ & 0.34 & 3.19 \\
\hline $\mathrm{nC} 23$ & 0.34 & 4.69 \\
\hline $\mathrm{nC} 24$ & 0.84 & 6.33 \\
\hline $\mathrm{nC} 25$ & 0.32 & 9.31 \\
\hline $\mathrm{nC} 26$ & 0.25 & 11.48 \\
\hline
\end{tabular}

\begin{tabular}{|c|c|c|}
\hline \multirow{2}{*}{$\begin{array}{c}\text { Straight-chain } \\
\text { organics }\end{array}$} & \multicolumn{2}{|c|}{ Concentration $/ \mu \mathrm{g} / \mathrm{L}$} \\
\cline { 2 - 3 } & Sample I & Sample II \\
\hline $\mathrm{nC} 27$ & 0.19 & 1.33 \\
\hline $\mathrm{nC} 28$ & 0.19 & 1.04 \\
\hline $\mathrm{nC} 29$ & 0.13 & 1.69 \\
\hline $\mathrm{nC} 30$ & 0.11 & 0.28 \\
\hline $\mathrm{nC} 31$ & 0 & 0.35 \\
\hline $\mathrm{nC} 32$ & 0 & 0.79 \\
\hline $\mathrm{nC} 33$ & 0 & 0.26 \\
\hline $\mathrm{nC} 34$ & 0 & 0.96 \\
\hline $\mathrm{nC} 35$ & 0 & 0.65 \\
\hline $\mathrm{nC} 36$ & 0 & 0.63 \\
\hline $\mathrm{nC} 37$ & 0 & 0.25 \\
\hline $\mathrm{nC} 38$ & 0 & 0.48 \\
\hline$\sum$ & 4.561 & 63.53 \\
\hline
\end{tabular}


of the eight types of aromatic hydrocarbons, including naphthalene, phenanthrene, thiophene, biphenyl, furan, flexor, pyrene class and fluorene, in sample II after electrochemical treatment were significantly reduced from $124.13 \mu \mathrm{g} / \mathrm{L}$ to $3.61 \mu \mathrm{g} / \mathrm{L}$. The total removal efficiency of the above-mentioned eight types of aromatic organics was $98.54 \%$. No triaromatic steroids and other (C27-29) organics were detected in the electrochemically treated wastewater, thereby indicating that these two types of organics were removed. The degradation rate of biphenyl organics was the lowest. Table 4 illustrates that the types of straightchain organics were increased by eight from C14-C30 to $\mathrm{C} 14-\mathrm{C} 38$, and the concentration was increased from $4.56 \mu \mathrm{g} / \mathrm{L}$ to $63.53 \mu \mathrm{g} / \mathrm{L}$ after electrochemical treatment. A large number of active free radicals are generated during the advanced electrochemical treatment process, thereby resulting in the degradation of aromatic organics in wastewater. The concentration of straight-chain alkanes or molecular fragments produced by the degradation increased with the decrease in the types and concentration of aromatic organics in the aqueous solution, thereby showing that the types and concentration of straight-chain organics in the aqueous solution markedly increased but made a small contribution to the COD. Overall, the total COD was decreased.

\section{Conclusions}

This study provides valuable parameters regarding the characteristics of polymer-containing oil production wastewater. In the polymer-containing oil production wastewater, the COD value of the molecular weight over $0.45 \mu \mathrm{m}$ accounted for $21.98 \%$ of the total COD. The COD of substances with a molecular weight of less than $1 \mathrm{kDa}$ accounted for $55.71 \%$ of the total COD. This finding showed that the contribution to COD of pollutants with a molecular weight over $0.45 \mu \mathrm{m}$ and less than $1 \mathrm{kDa}$ in wastewater was $77.69 \%$. Sample II treated by advanced electrochemical oxidation treatment was analyzed. The COD value of the molecular weight of over $0.45 \mu \mathrm{m}$ accounted for $22.03 \%$ of the total COD. The COD of the components with a molecular weight less than $1 \mathrm{kDa}$ accounted for $54.21 \%$ of the total COD. The contribution of these two types of pollutants to COD was $76.24 \%$. The GC-MS and UV-Vis results showed the presence of hydrocarbons and hydrocarbon derivatives in wastewater. The total removal efficiency of the aromatic organics was $98.54 \%$ after electrochemical treatment. The prevalent pollutants that contributed the most COD in the wastewater include the following: naphthalene, phenanthrene, triaromatic steroids and flexor organics. The total removal efficiency of these four types of pollutants was $97.34 \%$. These results showed that the electrochemical technology has a significant effect on the degradation of soluble organic components of aromatic hydrocarbons.
The types and concentration of straight-chain alkanes or molecular fragments produced by the degradation increased but made small contribution to the COD. In the study of advanced treatment of oily wastewater, the focus should be on the complete degradation of straightchain hydrocarbons (C15-C26) and small molecular fragments.

\section{Acknowledgements}

The authors are grateful for financial support from the Scientific Research Foundation of Educational Commission of Hubei Province, China (Q20201315) and the National Science and Technology Major Project of China (No.2016ZX05025-003).

\section{Conflict of Interest}

The authors declare no conflict of interest.

\section{References}

1. YANG M.Y., JING B., CHEN W.J., YIN X.Q. Experimental study on COD composition and electrochemical degradation of wastewater in offshore oilfields. J Chin Chem Soc, 64 (1), 73, 2017.

2. WILLIAMS K.S., KHODIER A. Meeting EU ELV targets: Pilot-scale pyrolysis automotive shredder residue investigation of $\mathrm{PAHs}, \mathrm{PCBs}$ and environmental contaminants in the solid residue products. Waste Manage, 105, 233, 2020.

3. LOU Z.Y., DONG B., CHAI X.L., SONG Y., ZHAO Y.C., ZHU N.W. Characterization of refuse landfill leachates of three different stages in landfill stabilization process. J Environ Sci, 21, 1309, 2009

4. JIA X.Q., JIN D.Y., LI C., LU W. Characterization and analysis of petrochemical wastewater through particle size distribution, biodegradability, and chemical composition. Chin J Chem Eng, 27 (2), 444, 2019 [In Chinese].

5. VO A., FENG X., PATEL D., MOHAMMAD A., KOZAK D., CHOI S., ASHRAF M., XU X.M. Factors affecting the particle size distribution and rheology of brinzolamide ophthalmic suspensions. Int J Pharm, 586, 119495, 2020.

6. DONG T., NORISUYE T., NAKANISHI H., TRANCONG-MIYATA Q. Particle size distribution analysis of oil-in-water emulsions using static and dynamic ultrasound scattering techniques. Ultrason, 108, 106117, 2020.

7. PAN Z.J., GAO X.L., ZHU W., WANG D., DONG J. Experimental study on treating produced water by polyether sulphone hollow fiber ultrafiltration membrane. Membr Sci Technol, 31 (2), 95, 2011 [In Chinese].

8. XU M., FENG W.Y., LIN Q.Y., ZHANG Y., SU Z.H. Application of ultrafiltration membrane technique to concentrate Aspen P-RC APMP effluent. China Pulp Pap, 29 (7), 11, 2010 [In Chinese].

9. INNOCCENTIA S., GIULIA P., MATTHIAS C., ADRIAN C., PETER D.A., JONATHAN O. Targeted and non-target screening of persistent organic pollutants and organophosphorus flame retardants in leachate and 
sediment from landfill sites in Gauteng Province, South Africa. Sci Total Environ, 653, 1231, 2019.

10. WU X.G., JING B., CHEN W.J., YANG M.Y., YIN X.Q., CHEN W. Optical particle size distribution and petroleum hydrocarbon analysis of offshore produced water from the Bohai sea. Desal Water Treat, 99, 315, 2017.

11. YIN X.Q., JING B., CHEN W.J., ZHANG J., LIU Q., CHEN W. Study on COD Removal Mechanism and Reaction Kinetics of Oilfield Wastewater. Water Sci Technol, 76 (10), 2655, 2017.

12. REURINK D.M., BRINKE E.T., ACHTERHUIS I., ROESINK H.D.W., VOS W.M.D. Nafion-based lowhydration polyelectrolyte multilayer membranes for enhanced water purification. ACS Appl Polym Mater, 1 (9), 2543, 2019.

13. LI Y., LIU M., LI R., SUN P., XIA H., HE T. Polycyclic aromatic hydrocarbons in the soils of the Yangtze River Delta Urban Agglomeration, China: Influence of land cover types and urbanization. Sci Total Environ, 715, 137011, 2020.

14. WAN Y.C., DIAMOND M.L, SIEGEL J.A. Elevated concentrations of semivolatile organic compounds in social housing multiunit residential building apartments. Environ Sci Technol Lett, 7 (3), 191, 2020.

15. ENDO Y., FURUSAWA M., SHIMAZAKI T., TAKAHASHI Y., NAKAHARA Y., NAGAKI A. Molecular weight distribution of polymers produced by anionic polymerization enables mixability evaluation. Org Process Res Dev, 23 (4), 635, 2019.

16. VRIJSEN J.H., RUBENS M., JUNKERS T. Simple and secure data encryption via molecular weight distribution fingerprints. Polym Chem, 11 (40), 6463, 2020.

17. ALIPOUR Z., AZARI A. COD removal from industrial spent caustic wastewater: A review. J Environ Chem Eng, 8 (3), 103678, 2020.

18. SARVAJITH M., REDDY G.K.K., NANCHARAIAH Y.V. Aerobic granular sludge for high-strength ammonium wastewater treatment: Effect of $\mathrm{COD} / \mathrm{N}$ ratios, longterm stability and nitrogen removal pathways. Bioresour Technol, 306, 123150, 2020.
19. SAKAYA K., SALAM D.A., CAMPO P. Assessment of crude oil bioremediation potential of seawater and sediments from the shore of Lebanon in laboratory microcosms. Sci Total Environ, 660, 227, 2019.

20. UGOCHUKWU U.C., ONUORAH A.L., OKWUDELUNZU V.U., ODINKONIGBO U.L., ONUORA O.H. Effects of power station and abattoir on PAH input into sediments of Oji River: ecological and human health exposure risks. Environ Monit Assess, 191, 775, 2019.

21. FRANCO J.H., SILVA B.F.D., DIAS E.F.G., DE CASTRO A.A., RAMALHO T.C., ZANONI M.V.B. Influence of auxochrome group in disperse dyes bearing azo groups as chromophore center in the biotransformation and molecular docking prediction by reductase enzyme: Implications and assessment for environmental toxicity of xenobiotics. Ecotoxicol Environ Saf, 160, 114, 2018.

22. ONA-RUALES J.O., RUIZ-MORALES Y. Prediction of the ultraviolet-visible absorption spectra of polycyclic aromatic hydrocarbons (dibenzo and naphtho) derivatives of fluoranthene. Appl Spectrosc, 71 (6), 1134, 2017.

23. GONCALVES R.P., MARCO P.H., VALDERRAMA P. Thermal edible oil evaluation by UV-Vis spectroscopy and chemometrics. Food Chem, 163, 83, 2014.

24. LI J., LI P., JIN C., ZHAO Y., GUO L., JI J. Treatment of municipal landfill leachate by electrochemical oxidation: assessing operating variables and oxidation products. Environ Eng Sci, 36 (12), 1503, 2019.

25. NURHAYATI E., BAGASTYO A.Y., HARTATIK D.D., DIRESTIYANI L.C. The enhancement of biodegradability index of mature landfill leachate by electrochemical oxidation process using boron-doped diamond and dimensionally stable anode. Res Chem Intermed, 46, 4811, 2020.

26. KAUR P., KUSHWAHA J.P., SANGAL V.K. Evaluation and disposability study of actual textile wastewater treatment by electro-oxidation method using $\mathrm{Ti} / \mathrm{RuO}_{2}$ anode. Process Saf Environ Prot, 111, 13, 2017.

\section{Supplementary Material}

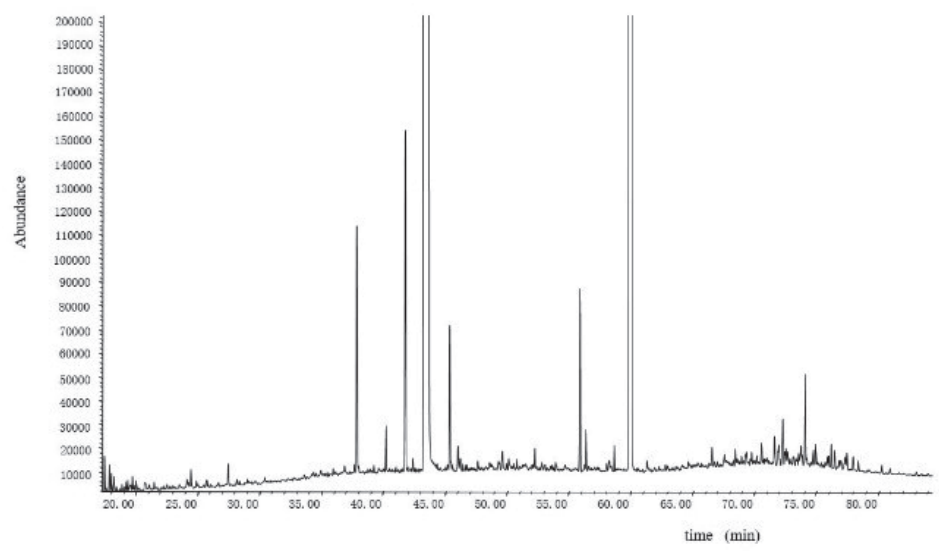

Fig. S1. Sample I aromatic hydrocarbons. 


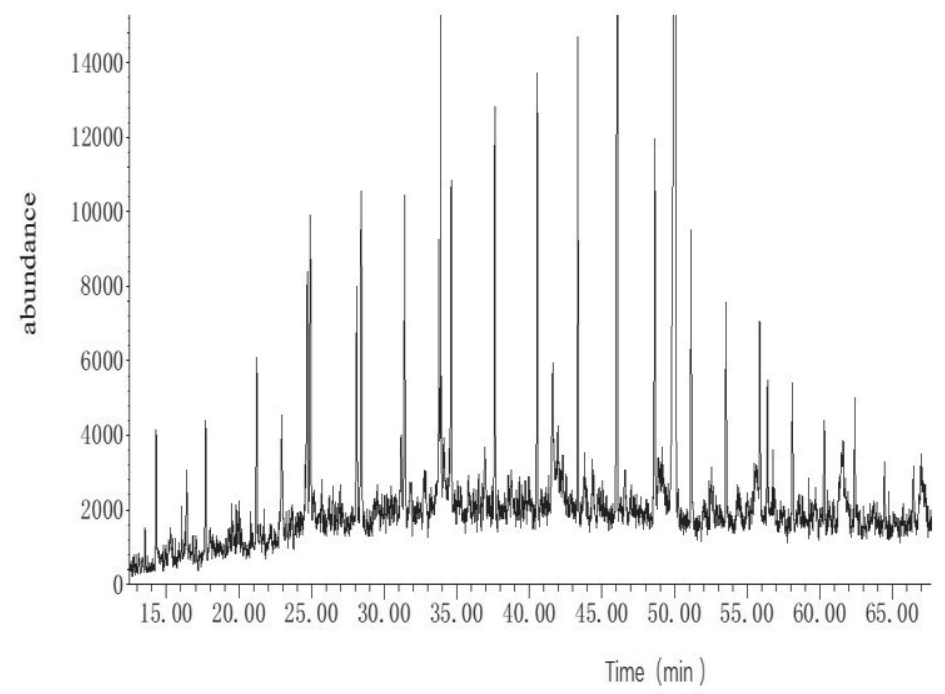

Fig. S2. Sample I alkanes.

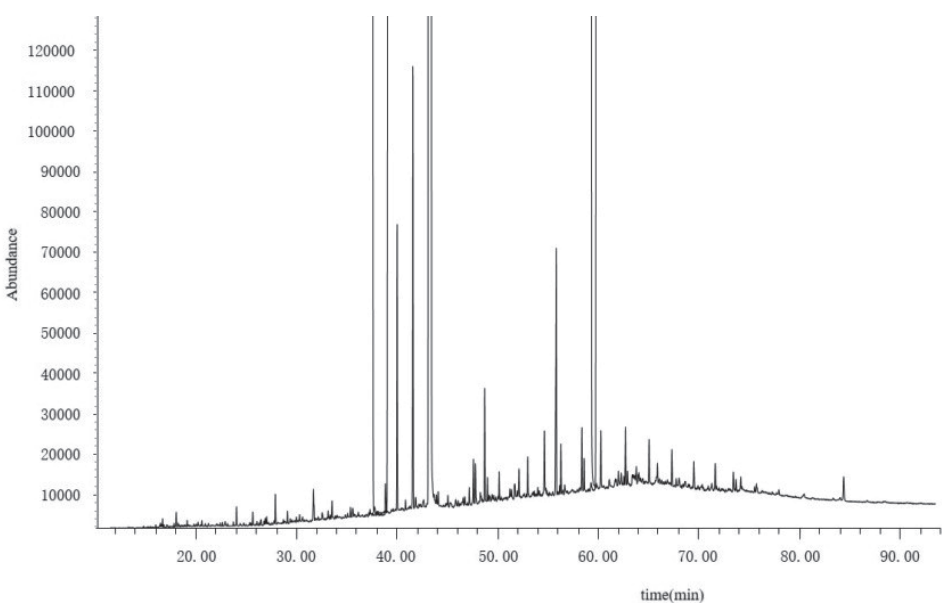

Fig. S3. Sample II aromatic hydrocarbons.

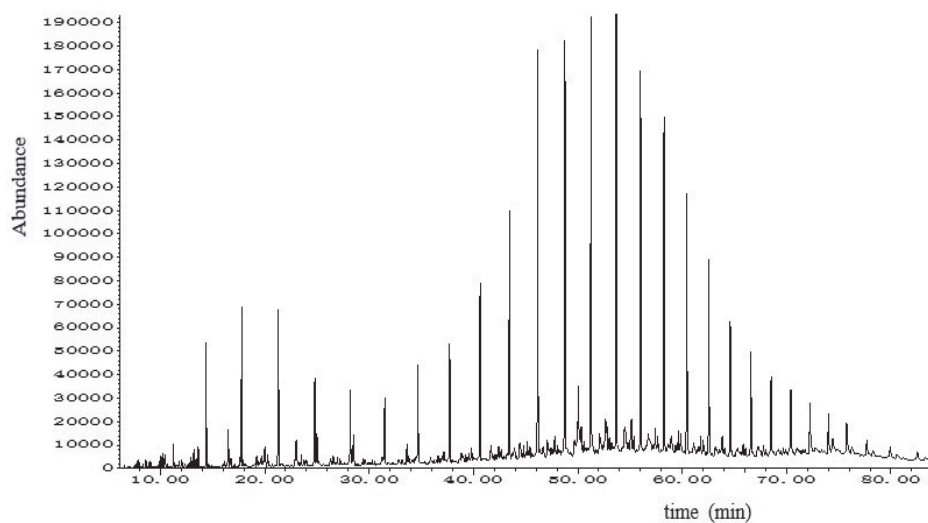

Fig. S4. Sample II alkanes. 